\title{
PERCEPÇÃO SOBRE A PRÁTICA DE ENFERMAGEM EM CENTROS DE ATENÇÃO PSICOSSOCIALa
}

\author{
Francisca Bezerra de OLIVEIRA ${ }^{b}$ \\ K arla M aria Duarte SI LVAC \\ Joana Celine Costa e SILVA ${ }^{d}$
}

\section{RESUM 0}

A prática de enfer magem em serviços de atenção em saúde mental é algo construído no cotidiano das instituições, a partir das interações estabel ecidas entre profissionais, usuários e familiares. E sta pesquisa é do tipo exploratória, com abordagem qualitativa. O bjetiva conhecer a percepção dos profissionais dos Centros de A tenção P sicossocial sobre a prática cotidiana do(a) enfer meiro(a) nesses serviços. A coleta de dados foi real izada por meio de entrevistas semi-estruturadas. Da análise temática dos dados emergiram dois temas: a enfer meira estabelece o primeiro contato com o usuário; a enfer meira é o el o entre profissionais e usuários. Os resultados demonstram que a prática de enfermagem em saúde mental busca construir ações inventivas, estabelecer vínculos afetivos, acolhimento e desmistificar o "olhar" que vêno diferente, no "louco" uma ameaça. É uma prática que enfatiza o sentido de produção de vida, do aumento da capacidade do usuário de estabelecer trocas sociais, possibilitando-Ihe maior autonomia.

D escritores: Saúde mental. Enfermagem psiquiátrica. A colhimento.

\section{RESUMEN}

L a práctica de enfermería en servicios de atención en salud mental es al go construido en el diario delas instituciones, a partir de las interacciones establecidas entre profesionales, usuarios y familiares. E sta investigación es de tipo exploratoria, con abordaje cual itativo. T iene por objetivo conocer la percepción de los profesionales de los Centros de A tención Sicosocial sobre la práctica diaria del (de la) enfermero (a) en esos servicios. E I aporte de datos ha sido realizado con cita semiestructurada. D el análisis temático de los datos han emergido dos temas: la enfermera establece el primer contacto con el usuario; la enfermera es el enlace entre profesionales y usuarios. L os resul tados demuestran que la práctica de enfermaría en la salud mental busca construir acciones inventivas, establecer víncul os afectivos, acogida y deshacer la "mirada" que ve en lo diferente un loco amenazador. E s una práctica que enfatiza el sentido de producción de vida, del aumento de la capacidad del usuario de establecer cambios sociales, posi bilitándole mayor autonomía.

Descriptores: Salud mental. E nfermería psiquiátrica. A cogimiento.

T ítulo: Percepción sobre la práctica de enfermería en Centros de A tención Sicosocial.

\section{ABST RACT}

The practice of nursing in the psychosocial care centers in mental health is something made in the institutions daily from established interactions among professionals, patients, and the patient' sfamily. T his research is somew hat exploratory and has a qualitative approach. It aims to know the daily practice of professionals from P sychosocial $\mathrm{CareC}$ enters on daily practice of the nurse in this kind of work. The coll lected data were made by means of-semi-structured interviews. F rom the thematic anal ysis of the data, tw o themes appeared: the nurse establi shes the first contact with the patients; that is, the nurse is the link betw een doctors and patients. The results show that the practice of nursing in mental health searches to construct inventive actions, establ ish affective ties, wel come the patients, and contradict the different way by which some uncommon people are seen the "insane" as a threat. It is a practice that emphasizes the meaning of life production, that is, the increase of the patient's capacity to establish social exchanges, giving him/ her greater autonomy.

D escriptors: M ental health. P sychiatric nursing. U ser embracement.

$T$ itle: Perception about the nursing practice in the P sychosocial Care Centers.

\footnotetext{
a T rabalho parte da pesquisa "Assistência psiquiátrica na Paraíba: da prática psiquiátrica asilar à prática de reabilitação psicossocial" do Programa Institucional de Bolsas de Iniciação Científica (PIBIC) realizada pela Universidade Federal de Campina Grande (UFCG) e financiada pelo Consel ho N acional de D esenvolvimento Científico e T ecnológico (CN Pq).

${ }^{b}$ D outora em Enfermagem, Professora Associada I da U F CG, Campus de Cajazeiras, Paraíba, Brasil.

'A cadêmica de enfermagem da U F CG, Campus de Cajazeiras, Bolsita PIBIC/CN Pq/ U F CG no período de agosto de 2004 a julho de 2006 , Cajazeiras, Paraíba, Brasil.

dA cadêmica de enfermagem da U F CG, Campus de Cajazeiras, Bolsista PIBIC/ CN P / U F CG no período de agosto de 2006 a jul ho de 2008 ,

Cajazeiras, Paraíba, Brasil.
} 


\section{INT RODUÇÃO}

Historicamente a assistência psiquiátrica está marcada pela exclusão do louco em espaços de inter nações devido sua "periculosidade" social, pois o louco era visto em meio à pobreza e a marginalidade, e os manicômios constituíam formas de preservar a ordem social e evitar que os efeitos da desordem se irradiassem para a sociedade. Desse modo, à assistência psiquiátrica no Brasil, até o final dos anos 90 do século XX estava centrada predominantemente no modelo asilar, ou seja, no modelo "hospitalocêntrico", que tem como princípio básico o isolamento do doente mental.

0 isolamento do louco em instituições psiquiátricas ocorreu, também, em virtude dos profissionais de saúde mental considerarem que a "inofensividade" dos loucos era apenas aparente. 0 caráter imprevisível e estranho do "louco" transformava-o num "perigo" real que deveria ser eliminado do meio social através de sua reclusão no hospital psiquiátrico(1).

A loucura ao ser isolada no hospício significou uma maneira eficiente "de controlar o 'perigo' que ela representava circulando livremente pelas ruas da cidade. $N$ esse sentido, a defesa da criação de um estabelecimento para alienados inscreviase em um projeto político mais abrangente que objetivava a normatização dos comportamentos da população urbana [ ...] "(1).

O bserva-se que a função da instituição asilar se constituiu numa forma de controlar, excluir e segregar o doente mental do convívio social. 0 trabalho de controle sobre o doente era exercido pela enfermagem psiquiátrica.

Sobre a prática de enfermagem psiquiátrica em instituições de model o tradicional é importante destacar que além da vigilância e do controle sobre o doente, herança comum da constituição da enfermagem moder na, o que o(a) enfermeiro(a) faz nos hospícios é reproduzir mecanicamente o saber médico, administrando a medicação prescrita, sem saber o nome do paciente, sua história, sua individualidade ${ }^{(2)}$.

No entanto, nas últimas décadas do sécul $0 X X$ ocorreram críticas ao modelo asilar, surgindo novas práticas e for mas de cuidar e novas modalidades de atenção em saúde mental, tendo como princípio básico a desinstitucional ização.

N o Brasil, a desinstitucionalização, que tem Basaglia como protagonista deste movimento(3), tem sido a palavra-chave da reforma psiquiátrica brasileira. A reforma é compreendida como um processo de desconstrução do paradigma asilar, como invenção de novas possibilidades de atenção em saúde mental; vai de encontro a toda política de sucateamento dos serviços públicos e da desassistência. Representa, sobretudo, a criação de complexos serviços de cuidados como os Centros de A tenção Psicossocial (CAPS), N úcleos de A tenção Psicossocial (NAPS), residências ter apêuticas, etc., e práticas ancoradas em um cuidar solidário, criativo e inter disciplinar ${ }^{(4)}$

0 primeiro CAPS criado foi o da cidade de São Paulo, em 1987, constituindo-se em um centro de irradiação da experiência para todo o país. A tualmente, no Brasil, existem mais de 1.000 CAPS cadastrados e em funcionamento no Sistema Ú nico de Saúde (SUS), desde o Sertão da Paraíba até o Rio G rande do Sul. A Política de Saúde M ental do SU S segue as determinações da Lei no 10.216/ $2001^{(5)}$ eé referendada pela III Conferência N acional de Saúde $M$ ental ${ }^{(6)}$ e conferências nacionais de saúde.

O CAPS é uma estrutura intermediária entre a hospital ização e a vida comunitária, destinado a atender pessoas com transtor nos mentais graves: psicóticos, obsessivos compulsivos, depressivos, entre outros, sempre acompanhados de desajustamento sócio-cultural e econômico.

Assim, postula-se que as práticas nos novos serviços substitutivos em saúde mental devem se constituir em atividades humanas criadoras, afetivas e interdisciplinares, ou seja, atividades que estão sempre em processo de desconstrução/ construção de conceitos sobre o universo da loucura, como também maneiras de lidar com o sofrimento psíquico que possam contribuir para a discussão sobre a reforma psiquiátrica em curso em nosso país.

Eleger o recorte empírico a percepção da prática do(a) enfermeiro(a) em serviços substitutivos em saúde mental, como objeto deste estudo, constitui-se uma busca de discussão e reflexão sobre o processo de transformação teóricoprátrico de atenção em saúde mental, sobre o modo de inserção do enfermeiro nessas modalidades de atenção, procurando contribuir para o debate sobre a reforma psiquiátrica no Estado da Paraíba. Sendo assim, essa pesquisa tem como objetivo conhecer a prática cotidiana do(a) enfermeiro(a) em centros de atenção psicossocial, a partir da percepção dos demais profissionais da equipe. 


\section{MET ODOLOGIA}

T rata-se de um estudo de natureza exploratória, com abordagem qual itativa, desenvolvido nos Centros de Atenção Psicossocial (CAPS) de Cajazeiras e Sousa - Paraíba. Para a coleta de dados foram realizadas entrevistas semi-estruturadas com os profissionais de nível superior que desenvolviam atividades nos referidos CAPS. As entrevistas continham um roteiro básico, tendo como questões norteadoras: fale sobre a prática cotidiana do(a) enfermeiro(a) no CAPS; descreva a relação do(a) enfer meiro(a) com os profissionais da equipe; fale sobre a relação interpessoal estabelecida pelo(a) enfer meiro(a) com os usuários e os familiares desse serviço. $\mathrm{N}$ a oportunidade, obteve-se a autorização dos coordenadores dos serviços para a real ização da pesquisa, e passou-se à fase da col eta de dados. Após a explicitação do objetivo da pesquisa, contou-se com o consentimento livre e esclarecido dos profissionais entrevistados, garantindo-Ihes a confidencial idade de suas respostas, obedecendo aos aspectos éticos e legais da Resolução 196/ 96, do Consel ho $\mathrm{N}$ acional de Saúde ${ }^{(7)}$. Os sujeitos concordaram em participar do estudo, bem como com a divulgação do resultado da pesquisa no meio científico. D estaque-se que esta pesquisa foi primeiramente aprovada pelo Comitê de Ética em Pesquisa, do Centro de Ciências da Saúde, U niversidade Federal da Paraíba.

As entrevistas com os profissionais foram realizadas nos próprios serviços. Foram entrevistados todos os profissionais de nível superior que concordaram em participar desta pesquisa, totalizando 14 profissionais, sendo seis do CAPS de Cajazeiras: um psicóloga, um assistente social, um terapeuta ocupacional, um pedagoga, um médica psiquiátrica, um terapeuta corporal; e oito do CAPS de Sousa: dois psicólogas, um psicopedagoga, um nutricionista, um médicos psiquiátricos, um assistente social e um terapeuta ocupacional. As entrevistas foram transcritas pelas pesquisadoras.

Os dados coletados foram anal isados a partir de uma abordagem qual itativa, tendo como respaldo teórico autores que abordam a temática da reforma psiquiátrica ${ }^{(8,9)}$. 0 primeiro passo para a organização do material foi as leituras exaustivas das entrevistas, possibilitando uma imersão nos textos para extrair deles as informações do contexto. A partir dessas leituras foi elaborado um texto entremeado por comentários, baseado nas informações registradas no momento da realização da pesquisa, o qual permitiu adentrar nas reflexões sobre a prática cotidiana do(a) enfermeiro(a) e sua inserção nos novos serviços de assistência em saúde mental. Do texto elaborado, emergiram duas temáticas: a enfermeira estabelece o primeiro contato com o usuário; a enfermeira como elo entre profissionais e usuários.

\section{RESULTADOS E DISCUSSÕES}

\section{A enfermeira estabelece o primeiro contato com o usuário}

D e acordo com os entrevistados, ficou evidenciado que o(a) enfermeiro(a) estabelece o primeiro contato com o usuário. Este contato constitui-se como fundamental, uma vez que significa o momento de construção de víncul os de confiança com o profissional e com o serviço, de modo a possibilitar acolhimento, escuta comprometida e relações interpessoais entre profissionais, usuários e familiares.

Ao refletir sobre as relações interpessoais estabel ecidas entre o(a) enfermeiro(a) e o usuário, convém ressaltar que "[ ...] as enfermeiras se dão conta que o paciente é um ser de relações, ser social de direitos e desejos. U m ser que na relação com outros experimenta sentimentos diversos, confia, busca apoio. Parece ser possível afirmar que é nos contatos onde acontecem trocas que se criam possibilidades para a re-construção do paciente como sujeito ativo - pode falar, circular, participar, fazer escolhas"(10).

$\mathrm{N}$ essa perspectiva é importante frisar a fala a seguir de um dos participantes do estudo:

A relação da enfermeira com o usuário é de amor, de dicação, de busca por parte da enfermeira para conseguir, ou melhor, para reabilitar estepaciente para conviver em sociedade, junto com a família (E ntrevista 2, $N$ utricionista).

Esta fala demonstra a necessária relação dialógica entre o(a) enfermeiro(a) e o usuário, estabelecendo o diálogo, o confronto, a troca, uma interação afetiva. I sto possibilita consider ar o usuário como um ser que se re-significa como sujeito, no convívio e inter ação com os outros, nos grupos terapêuticos, nas assembléias, nas oficinas etc. 
$N$ as novas modalidades de atenção em saúde mental, o rel evante é o sujeito e não a doença. D esse modo, conforme os depoimentos dos profissionais dos CAPS, os(as) enfer meiros(as) buscam privilegiar como recorte, o sofrimento psicossocial, a fragilidade, a pessoa. É pela presença e pelo envolvimento com o sujeito adoecido que se podem formar vínculos entre profissionais e usuários.

Em outra pesquisa realizada abordando a perspectiva do(a) enfer meiro(a) sobre a sua prática cotidiana nos CAPS, no E stado da Paraíba, observou-se que tal prática deve incluir, necessariamente, "o relacionamento ter apêutico entre enfermeiro(a) e paciente. U m bom profissional de enfermagem é aquel e que sabe cultivar essa relação através de trocas de experiências e de vínculos afetivos. I mplica, ainda, na capacidade de sensibilizar-se, de partilhar do sofrimento e garantir ao usuário um tratamento de qualidade"(11).

D essa for ma, essa postura ter apêutica desenvolvida nos CA PS se contrapõe à prática tradicional em psiquiatria que se caracteriza por uma relação passiva do usuário em relação ao profissional. N os novos serviços de atenção psicossocial a prática do(a) enfermeiro(a) não é al go "dado", mas uma prática em processo de construção engendrada no diálogo com os atores sociais (profissionais, usuários efamiliares). E stes parceiros compartilham saber es, for ças concretas da comunidade viabilizando ações que estabelecem vínculos e promovem a cidadania e a autonomia do usuário.

0 vínculo de confiança e 0 acol himento constituem-se, portanto, como elementos necessários para uma inter ação comprometida e efetiva com 0 usuário, uma vez que o (a) enfermeiro(a) é o profissional da equipe que estabel ece o primeiro contato com o usuário, conforme está enfatizado na fala a seguir:

É o enfermeiro que faz com que ele [ o usuário] adquira confiança nele [ 0 enfermeiro] e nos profissionais. M uito dos probl emas, angústia, ele quer compartilhar com o enfermei ro por ter o primeiro contato ( $E n$ trevista 4, Psicóloga).

0 tratamento de pessoas com transtornos mentais e/ ou sofrimento psíquico não deve ter como objetivo a "cura", compreendida como elemento ordenador da subjetividade do sujeito, de busca de retorno a um estado univer sal de normalidade. A ênfase deve ser colocada no sentido de produção de vida, do aumento da capacidade do usuário de estabelecer trocas sociais, possibilitando maior autonomia deste. Este ganho social está representado pela melhoria da qualidade de vida proporcionada às pessoas com transtornos mentais que antes se encontravam excluídas do meio social e familiar, e hoje, com a diminuição de seus sofrimentos, estudam, passeiam, interagem.

\section{A enfermeira é o elo entre profissionais e usuários}

A partir dos depoimentos dos entrevistados foi possível identificar que o(a) enfermeiro(a) se car acteriza como elo entre os profissionais da equipe e os usuários. Pode-se observar que a participação da enfer meira na equipe parece ser a mediação necessária para que ocorra o entrosamento, conforme observado no relato a seguir:

A prática da enfermeira aqui no CAPS émuito atuante. Existe uma relação, todo um envolvimento, a enfermeira tem sido uma peça chave para que tudo se concretize e haja todo um andamento do serviço, desde o atendimento do usuário quando el e chega em crise, até a sua alta [ .... . A enfermeira éum elo importantíssimo. E u creio assim, ela éum elo entretodos os profissionais, então tudo que acontece, a gente sempre procura a orientação dela, saber como está aquel epaci enteno diaa-dia [...] (Entrevista 5, A ssistente social).

A preende-se nesta fala que todos os profissionais estão intimamente envolvidos no processo de reabilitação do usuário. E m um dos serviços, o(a) enfermeiro(a) possui uma carga horária maior nas atividades. Por isso, sua relação com o usuário se torna mais próxima, acompanhando-o desde sua acol hida e tratamento na instituição e sua (re)integração na sociedade. A crescente-se a isso a necessidade do trabalho em equipe, na perspectiva da interdisciplinaridade.

A necessidade do trabal ho interdisciplinar no campo da saúde mental decorre do fato de que o "adoecer psíquico" não é um fenômeno homogêneo e simples, mas complexo. Sendo assim, as formas de acesso ao "sofrimento-existência" devem ser as mais diversificadas possíveis, buscando construir práticas que ousem imaginar 0 ainda não imaginado e 0 ainda não experimentado, desenvolvendo formas de cuidados que atendam a totalidade do sujeito em sofrimento psíquico(4). 
Percebe-se que o(a) enfermeiro(a) se identifica como profissional de referência para os demais profissionais de nível superior etécnico, bem como para os usuários, isto é, al guém significativo para 0 serviço que possibilita trocas e mudanças de um "olhar" puramente técnico para um "olhar" humano, visando à relação inter pessoal. Os relatos a seguir possibilitam compreender esta questão:

E la tem uma referência, a gente fala assim um refe rencial muito grande com o usuário, uma referência de apoio, de apoio psicológico, até mesmo com nós profissionais (E ntrevista 5, Assistente Social).

[ ...] realmenteéuma dedicação total e os usuários têm uma identificação muito grandecom a enfermeira aqui dentro do CAPS, a maioria a tem como técnico de refe rência (Entrevista 3, Psicóloga).

N este estudo ficou caracterizado que o início do trabalho dos profissionais nos serviços pesquisados foi permeado de medo, ansiedade, incerteza e conflito. Isso, possivelmente, seja justificado pela pouca experiência destes no campo da saúde mental, e por ser o CA PS um espaço que exige práticas criativas, fundamentadas na interdisciplinaridade, necessitando transitar nas diversas ár eas do conhecimento; desconstruindo práticas silenciadoras e reconstruindo práticas voltadas para a criatividade, para as reais necessidades do usuário; configurando-se como recusa ao modelo psiquiátrico asilar, que centra o tratamento no poder do médico, na hierarquização das funções e na objetividade da doença mental.

$\mathrm{U} \mathrm{m}$ aspecto que merece destaque é o fato de que em uma das instituições que se realizou este estudo, o(a) enfermeiro(a) desempenhava atividades, simultaneamente, em um serviço tradicional e um serviço substitutivo, que é o CA PS. E sta realidade pode ser evidenciada pelas seguintes falas:

E la já trabalhava num hospital psiquiátrico desta cidade E u especialmente, no primeiro momento tivemedo de que a prática dela aqui no CAPS desse continuidade a prática da instituição asilar, mas vi que em nenhum momento esta prática foi desenvolvida aqui. E la abraçou a reforma psiquiátrica, e faz um trabalho de acordo com a reforma (E ntrevista 10, A ssistente So(ial).

A enfermeira já tinha experiência em Saúde M ental, e foi quem realmente nor teou todos da equipe em forma- ção. D esta forma, com a experiência dela, ajudou bastantena prática em SaúdeM ental (E ntrevista 9, Psicóloga).

A partir desses depoimentos vê-se que embora o(a) enfermeiro(a) venha desenvolvendo uma prática em uma estrutura asilar não houve interferência negativa na sua prática nos serviços objeto desta discussão. Ao contrário, esta sua vivência trouxe vantagens à atuação no CAPS, pela experiência que ela possuía no campo da psiquiatria, possibilitando orientar e nortear essa nova modalidade em Saúde M ental.

As atividades desenvolvidas pelas enfermeiras nos CAPS do Alto Sertão Paraibano vão além da administração de medicamentos, alimentação e higiene, que são a essência da assistência de enfermagem psiquiátrica tradicional. D estacam-se também as seguintes atividades: triagem, visita domiciliar, reuniões de equipe, orientação ao usuário e aos familiares sobre a doença, o tratamento e o uso de medicamentos, supervisões dos serviços de enfermagem, participação em eventos festivos (carnaval, semana santa, festa junina, natal e comemoração dos aniver sariantes do mês), pal estras na comunidade, participação em grupos terapêuticos, entre outras. E ssas atividades são real izadas com a participação dos demais profissionais que compõem a equipe. 0 encaminhamento dos usuários para as atividades é discutido nas reuniões entre os profissionais, sendo estabelecido a partir das necessidades dos mesmos.

A triagem é uma atividade desenvolvida pelo(a) enfermeiro(a) nos serviços abordados neste estudo. Essa atividade se constitui o momento de acolher a pessoa com transtorno mental e valorizar o conteúdo de suas falas, buscando identificar o perfil da pessoa a ser atendida. $\mathrm{N}$ a triagem, procura-se dar direção ao tratamento, que será baseado na problemática apresentada pelo usuário. É importante que a triagem seja realizada no mínimo por dois profissionais da equipe, "pelo fato do sofrimento psíquico ser decorrente de fenômenos multifacetados (biológico, social, cultural, psicológico e político) [ ...] , pois uma abordagem interdisciplinar, uma escuta diferenciada facilita a compreensão desse fenômeno complexo"(4).

A visita domiciliar compreendida como um projeto também faz parte da estratégia terapêutica dos serviços investigados, sendo realizada por profissionais de nível superior e médio, com uma 
maior participação do(a) enfermeiro(a) e da assistente social, devido aos questionamentos dos familiares estarem relacionados à medicação, ao tratamento e ao auxílio doença, embora envolva outras discussões. A visita domiciliar enquanto projeto terapêutico é um contraponto importante para os demais projetos, pois possibilita o conhecimento das reais necessidades dos usuários e familiares.

É fundamental a participação da família no tratamento do usuário em Saúde M ental. Destaque-se que a família nem sempre está preparada para lidar com o parente com transtorno mental, sente carência de infor mação qualificada e, muitas vezes, sente-se obrigada a dedicar grande parte do seu cotidiano para o cuidado ao mesmo. Os delírios, as alucinações e os comportamentos estranhos desestruturam as formas da família tratar o doente, que por sua vez sente-se frustrado, triste e com medo. A cul pa também passa a fazer parte do cenário familiar, que busca explicações em erros do passado para amenizar seu sofrimento. Por isso a partici pação dos familiares no tratamento, como também a vivência com outros familiares, passando a conhecer outros contextos, pode ser um caminho enriquecedor para todos os envolvidos no processo de reabilitação psicossocial dos sujeitos adoeci$\operatorname{dos}^{(12)}$.

A atividade grupal e individual é uma das ações desenvolvidas pelos(as) enfermeiros(as) nos CAPS. D estaca-se a atividade grupal por apresentar algumas vantagens: possibilita que 0 usuário se encontre no univer so, isto é, que possam sentir que o que experimenta como preocupante e ameaçador, os companheiros também experimentam ou já experimentaram; proporciona relações interpessoais em ambiente protegido pelo grupo; rapidez de resultados, pela oportunidade dos usuários de experimentarem o papel de terapeutas, encontrando formas de solucionar seus próprios problemas. E ssa atividade é realizada semanalmente nos dois CAPS pesquisados, objetivando trabalhar questões referentes ao uso da medicação (sintomas, dose, efeitos colaterais, etc.), abordando também temas como sexualidade, doenças sexualmente transmissíveis (DST s), higiene corporal e autoestima.

Parece ser possível inferir que a prática cotidiana do(a) enfermeiro(a) nos novos serviços de atenção psicossocial está sendo construída/ desconstruída na convivência com os demais profissio- nais e usuários, de modo a possibilitar práticas criativas, dinâmicas e trocas entre os vários saberes, tendo como eixo norteador o aumento do grau de autonomia e liberdade do usuário.

E nfim, o(a) enfermeiro(a) que atua no campo da saúde deve ser uma pessoa apaixonada pela produção da vida al egre, por uma estética da existência, por agenciamento de experiências subjetivas; deve desenvolver habilidades para proporcionar aumento da capacidade do sujeito adoecido de estabelecer trocas sociais no contexto sócio-cultural, bem como descobrir os "tesouros soterrados nos escombros" daquel es que apresentam sofrimento, dor na alma.

\section{CONSIDERAÇÕES FINAIS}

É possível afirmar que a mudança do pensar e agir da enfermagem psiquiátrica e em saúde mental passa pela busca de um "olhar" nas experiências singulares, inovadoras que estão sendo construídas e desenvolvidas nos municípios brasileiros - desde - Sertão da Paraíba ao R io G rande do Sul - que, de modos diferenciados, buscam concretizar a reforma psiquiátrica.

E sta pesquisa evidenciou, a partir da percepção dos demais profissionais da equipe, que a prática do(a) enfermeiro(a) nos serviços de atenção psicossocial constitui-se como fundamental, uma vez que este profissional quase sempre é responsável pela acolhida do usuário, estabelecendo vínculos afetivos, de confiança, de escuta e de relações interpessoais entre usuários e familiares. A enfermeira constitui-se como o profissional de referência para a maioria dos usuários dos CA PS pesquisados.

Além disso, foi observado que o(a) enfermeiro(a) representa o elo entre profissionais e usuários, a mediação necessária para que informações importantes acerca dos usuários circulem, haja maior interação entre profissionais e usuários, e continuidade no tratamento. O (a) enfermeiro(a) ao favorecer o envolvimento efetivo dos profissionais da equipe no processo ter apêutico estimula for mas de cuidados que atendem a totalidade do sujeito com transtorno mental.

Observou-se ainda, que a filosofia de trabaIho desenvolvida pelos(as) enfermeiros(as) nos CAPS do "Alto Sertão Paraibano" diferencia-se da prática tradicional em psiquiatria. A prática de atendimento nestes serviços busca construir ações in- 
ventivas, estabelecer vínculos afetivos e de confiança, e desmistificar o "olhar" que vê no diferente, no "louco", uma ameaça. A ssim, a ênfase deve ser colocada no sentido de produção de vida, do aumento da capacidade do usuário de estabelecer trocas sociais, possibilitando maior autonomia deste.

Desse modo, as atividades desenvolvidas pelas enfermeiras nos novos serviços de reabilitação psicossocial, diferentemente das instituições psiquiátricas tradicionais, vão além das funções tradicionais de super visão, administração de medicamento, alimentação e higiene. E sses profissionais participam de atividades de triagem, visita domiciliar, atividades grupais e individuais, reuniões de equipe, real izam pal estras na comunidade, participam de eventos festivos, etc.

A pesar desses avanços, as ações cotidianas de enfer magem apresentam ainda limitações, contradições e incertezas. E $m$ espaço flexível, aberto como deve ser o CAPS, demanda mais competência, criatividade do profissional que no modelo baseado no paradigma de medical ização da loucura. N essa modalidade de atenção, o fazer cotidiano coloca a necessidade de um trabal ho interdisciplinar, de for mas plurais de cuidar, em que os papéis profissionais estão em constante processo de transformação.

0 momento atual exige um repensar da prática de enfermagem e da sua inserção nos novos serviços em saúde mental. Sendo assim, deve-se fazê-la, numa perspectiva construtiva, criativa, humanística, crítica e reflexiva, deve-se dizer não a exclusão, e sim ao cuidar, a solidariedade, a liberdade, em uma dinâmica interdisciplinar.

No mundo atual per meado por relações fragmentadas, é imperativo colocar nossa razão e paixão na construção de uma sociedade mais tolerante, justa e participativa; na construção de práticas que acolha o desconhecido, conviva com a diversidade, compreenda que loucura não significa desrazão, que existe positividade na experiência da loucura, que "desordem" não se identifica com "não ordem", que os saberes são sempre imprevisíveis e inacabados, e defenda a verdade a serviço da liberdade.

Espera-se que este estudo possa contribuir para a formulação de políticas públicas voltadas para as reais necessidades dos usuários em saúde mental dos municípios de Cajazeiras e Sousa -
Paraíba, para o debate sobre a reforma psiquiátrica no Estado da Paraíba, e para a um repensar a inser ção e a prática do(a) enfermeiro(a) nos novos serviços.

\section{REFERÊ NCIAS}

1 Engel M G. Os delírios da razão: médicos, loucos e hospícios. Rio de Janeiro: F iocruz; 2001.

$2 \mathrm{M}$ iranda CL 0 parentesco imaginário: história de representação social da loucura nas relações do espaço asilar. São Paulo: Cortez; Rio de Janeiro: Editora da UFRJ; 1994.

3 Basaglia F. A instituição negada: relato de um hospital psiquiátrico. Rio de Janeiro: G raal; 1985.

4 O liveira F B. Construindo saberes e práticas em saúde mental. J oão Pessoa: E ditora da U F PB; 2002.

5 M inistério da Saúde (BR ). Lei ํㅜ 10.216, de 6 de abril de 2001: dispõe sobre a proteção e os direitos das pessoas portadoras de transtor nos mentais e redireciona o modelo assistencial em saúde mental. Brasília (D F ); 2001.

6 M inistério da Saúde (BR ), Consel ho N acional de Saúde. Relatório final da III Conferência Nacional de Saúde M ental: cuidar sim, excluir não. Brasília (DF ); 2002.

7 M inistério da Saúde (BR ), Conselho N acional de Saúde, Comitê $\mathrm{N}$ acional de Ética em Pesquisa em Seres H umanos. Resolução 196, de 10 de outubro de 1996: diretrizes e nor mas regulamentadoras de pesquisas envolvendo seres humanos. Brasília (DF); 1996.

8 A marante P. Sobre duas proposições relacionadas à clínica à reforma psiquiátrica. In: Quinet $\mathrm{A}$, organizador. Psicanálise e psiquiatria: controvér sias e convergências. Rio de Janeiro: Rios A mbiciosos; 2001. p. 103-10.

9 A marante P. 0 homem e a ser pente: outras histórias para a loucura e a psiquiatria. R io de J aneiro: F iocruz; 1996.

10 A guiar M G. A reinvenção do ser enfer meira no cotidiano da Casa de Saúde Anchieta e Núcleos de Atenção Psicossocial [ dissertação] . São Paulo: E scola de Enfermagem, U niversidade de São Paulo; 1995. 
11 Oliveira F B, Farias M CAD, Silva M F P, Souza JJA. Serviços de atenção psicossocial: a prática cotidiana do(a) enfermeiro(a). N ursing (São Paulo). 2006;96(9): 822-7.
12 M elman J. Família e doença mental: repensando a relação entre profissionais de saúde e familiares. São Paulo: E scrituras; 2001. (Coleção en-saios transversais).
Endereço da autora / Dirección del autor / Author's address:

F rancisca Bezerra de O liveira

Rua J oão Col eta, 25, ap. 4, Leopoldina

58900-000, Cajazeiras, PB

E-mail: oliveirafb@uol.com.br
Recebido em: 06/ 04/ 2009

A provado em: 21/ 12/ 2009 